\title{
Informing Library Patrons about Internet Technology
}

\author{
Dina Kanabar \\ J.V. Fletcher Library, USA \\ dkanabar@mailservmulc libmans
}

\author{
Vijay Kanabar \\ Boston University, USA \\ kanabar@buedu
}

\begin{abstract}
In order to introduce Internet technology literacy in the town of Westford (Boston Suburb) a new series of workshops were introduced during the winter of 2000. This paper describes the strategy used to inform Westford community about the workshop and also presents an outline of the course topics and summary of research results generated from the participant's feedback and their experiences with the workshop.
\end{abstract}

Keywords. Internet Technology, Informing Patrons, Curriculum

\section{Introduction}

The town of Westford is home to several telecommunication and Internet companies, and has residents that are very interested in Internet technology. In spring 2000, the J.V. Fletcher Library became proactive in offering basic Internet classes for young adults, adults and seniors. This paper concentrates on our experience with the above course offerings and provides a summary of research conclusions based on feedback from patrons. It also describes methods used to inform the community about the course workshops and methods used to teach such a workshop.

\section{Motivation}

The Internet and the related development of web technologies for engineering, science, business, and virtually every field of human endeavor have dramatically increased the need for education and training in the field of information technology (Bassi, 1999). There is a need subsequently to provide Internet literacy help to the community. Even experienced web users need structured help in finding their way around the World Wide Web and searching for information. Crucially, the adult users who do not have any exposure to the Internet, unlike the younger generation need formal training and hands-on exercises. The best way to

Material published as part of this journal, either on-line or in print, is copyrighted by the publisher of Informing Science. Permission to make digital or paper copy of part or all of these works for personal or classroom use is granted without fee provided that the copies are not made or distributed for profit or commercial advantage AND that copies 1) bear this notice in full and 2) give the full citation on the first page. It is permissible to abstract these works so long as credit is given. To copy in all other cases or to republish or to post on a server or to redistribute to lists requires specific permission and payment of a fee. Contact Editor@inform.nu to request redistribution permission. learn about the Internet is by spending time on the Internet, but that time must be spent intelligently (Lehnert, 1988). It was our goal therefore to communicate intelligently with our patrons, understand their needs and then to provide appropriate hands-on training. Our goal was also to provide valuable training handouts. We wanted our patrons to use such handout as a source of reliable pointers to using the browser and to Internet resources.

\section{The Workshop}

At the outset the objective was to offer only one workshop, Basic Internet Skills, a hands-on approach to learning about the Internet and the World Wide Web. Our goal was to carefully guide beginners through such important topics as using the browser, saving favorites, creating a home page in your browser, getting a free e-mail account and learning to use email effectively and finally using search engines. Where possible our goal was to touch upon a variety of social issues as well. For instance patrons needed to be informed of security, and conducting credit card transactions over the Internet.

The highlight of the workshop was the hands-on component. Online exercises and simple projects were designed to reinforce learning and to help patrons become more comfortable with the Internet.

With the above goals in mind we created the Introductory Internet Workshop, designed for patrons who have little or no experience, and who want to use the Internet. We did not insist on any prerequisite such as word processor, spreadsheet, or other exposure to computing applications. Also we did not insist on any specific knowledge of a particular computer platform as a prerequisite. (The courses 
Informing Library Patrons

were taught on the MS Windows PC platform.) As our research conclusions will reveal this turned out to be a problem as we had a non-homogenous audience taking our courses.

\section{Informing Patrons}

Since a lot of time and effort was spent in designing the courses we felt that it was equally important to market our course offerings to the community. We used the following methods to reach our Westford community:

Web Site: Our library web site is frequently accessed by our patrons for a variety of purposes. We therefore advertised the workshops from our website:

WWW.Westfordlibrary.org. Using text and graphics we made it look fun, exciting and less intimidating especially for the inexperienced computer users.

Newspaper: The town of Westford has a popular community newspaper "Westford Eagle" that is published once a week. The Library used this venue to publicize the Internet workshops as we do for other services and programs every week. The Library Latest Online is also accessed from our website.

Cablevision: We also used an opportunity we had on Cablevision TV to reach as many people and inform the community that they could attend the Internet Workshop for free. We had the state representative, join us when we were promoting our library services through cablevision.

In-house postings: Colorful posters were created and posted in the Library. Several staff members were informed about content and nature of various computer and web courses. They directed questions to the systems librarian.

Town-Wide mailing: The library distributes and mails flyers to the residents of Westford informing them about the library programs and services offered for next six months.

Word of mouth: The Library staff and the Director were very proactive in mentioning to patrons, business community, friends, families, and neighbors about the Internet workshops that the Westford Library was offering.

All of the above strategies resulted in an overwhelming response. Sessions were books weeks in advance. And when the word of mouth trickled out from patrons who had actually taken the courses, we saw even more registrations.

\section{Content of the Course}

The following topics were covered: Learning to Use the Browser, Using Email, Log on to the Internet, Use Search Engines, Add web pages to favorites, Using ISP providers, Creating a free email account, Sending Email. Labs or demos on each of the above very conducted.

Here is a high level overview of the various topics and subtopics covered:

- Overview: Internet \& WWW

The Internet is a system connecting millions of computers around the world.

The World Wide Web, presents rich page content, including multimedia clips and even live radio and video.

- Web Pages \& Home Page

You view this content on Web pages by using a Web browser, such as Microsoft Internet Explorer (IE) or Netscape.

The top-level page of a Web site is called the home page

- Getting Around on the Internet

Each Web page has a specific address, sometimes known as a URL (uniform resource locator). eg., http://www.microsoft.com/MyFilename.htm

- What is WWW? What are the various domain names WWW indicates that the site is on the World Wide Web.

Web pages not on the WWW can be on an intranet (not visible to outsiders).

Com suffix indicates a commercial site

Edu is used for educational institutions

Org for organizations such as the Library

.Net is used by network/ISP providers

- Other Applications of the Internet

In addition to e-mail, you can use chat rooms and newsgroups to connect with people around the world. In a chat room you conduct a real-time typed conversation with one or more people, and in newsgroups (called bulletin boards) you read messages that have been posted, or post your own.

You can even make Internet phone calls using your computer or use a Video Cam to see and hear other people! 
- How do you get Started?

To start your browser you have to click START, select PROGRAM, select INTERNET EXPLORER (or NETSCAPE).

You may have a short cut icon on the desktop.

- Key Buttons on the Browser

- What is a Hyperlink?

To move around the Web one clicks text or pictures called links, or hyperlinks, which have addresses coded into them.

Your mouse pointer changes to a hand shape when it passes over a link.

The color of the link changes once after you have visited the site.

- URLs

Portal sites (such as msn.com) contain pre-selected links to popular pages.

Other popular portals are:

www.Yahoo.com

www.Altavista.com

www.Excite.com

www.Lycos.com

- Searching for Information

Clicking the Search button on the browser toolbar opens the Search bar, a separate pane on the left side of the window.

- Favorites

Keep your favorite sites or documents by adding them to your Favorites list.

You can easily add items to this list by using the

Favorites menu.

To access your favorite Web pages, click the Favorites button on the browser toolbar.

This opens the Favorites bar, which contains shortcuts to all your favorite items.

Clicking the History button will take you to a list of web sites you visited recently.

Useful to get back to a visited site if you are lost while surfing.

Changing the default Home Page that comes with the browser.

\section{Labs and Demos}

In order to make a course such as web technology interesting we used the following strategy. We incorporated a lot of Demos during the slide presentations and followed this
D. Kanabar and V. Kanabarr

up with hands on exercise from a lab guidebook. Figure 1 illustrates a demonstration for searching and Figure 2 illustrates a demonstration for favorites.

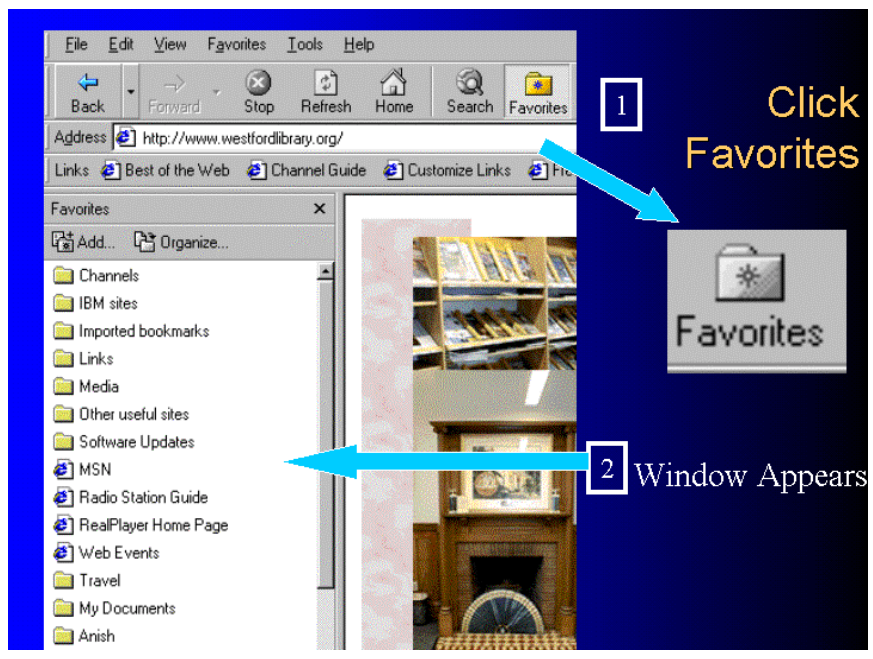

Figure 1: Demonstration of Favorites

These hands on exercises were very useful as they provided step-by-step instructions to key concepts. For many patrons this was truly a valuable experience. Sample stepby-step instructions and lab exercises are listed below:

\section{Lab 1: Using the Browser}

Type the URL "http://www.westfordlibrary.org"

1. Click the Enter button.

2. Click the Directions button.

3. Click the Back button.

4. Click the Forward button.

5. Click the Refresh button.

6. Click the Home button.

7. Click the Search button - search the Internet for the word Westford.

8. Click the Favorites button.

\section{Lab 2: Search Tools}

1. Use Yahoo to find a chocolate chip recipe.

2. Use Yahoo to locate the address of any Boston area University.

On your own return to the Westford Library Homepage, click the Departments button and select Periodicals option on the right hand window. Browse through some of the magazines. 


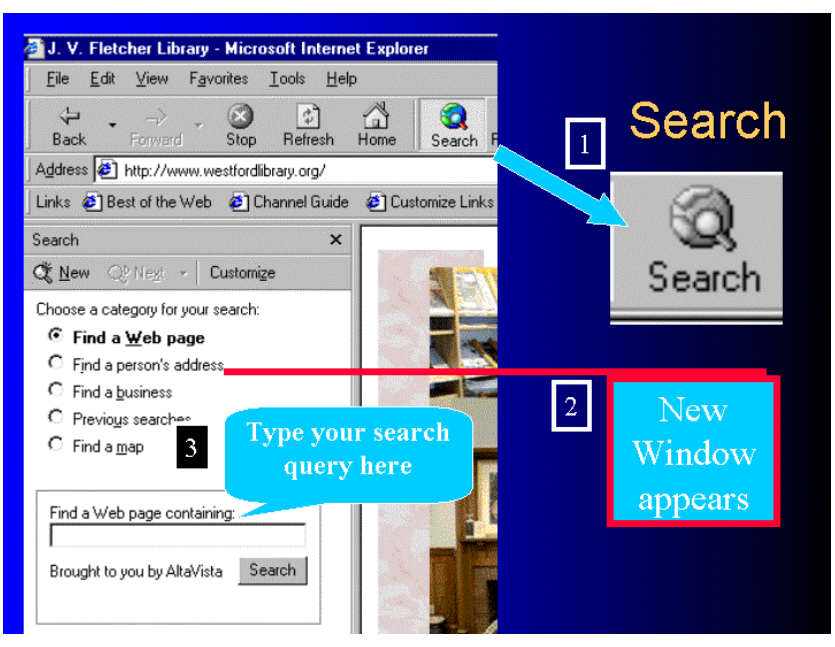

Figure 2: Lab Involving Search

\section{Conclusions from Initial Offerings}

We used an opportunity to conduct a dry run of the course on two willing seniors. That gave us the opportunity to make some revisions to the course and the confidence to conduct the workshop live.

The actual workshops turned out to be a pleasant experience for the instructor and the participants. The classroom set up was informal and the presentation very interactive. Different days were scheduled and day and evening hours were slotted so that we could get both working adults and stay at home patrons or seniors.

A formal evaluation instrument was designed to collect feedback from the patrons. This section summarizes some of the feedback and provides our conclusions from the initial offerings....

More than $95 \%$ of the patrons responded with a perfect rating on several categories dealing with the course content and the instructor's ability to deliver the content effectively. Some of the comments are listed below:

"I thought is was fantastic! I felt it was the right amount of content for an intro class."

"I learned soooo much! Thank you. I paid $\$ 80$ for a basic Web class and did not learn as much. Honest!"

“This class is great for beginners, I'm glad you offer this course."

"Need more hands-on time. Handout was helpful."

"Follow up workshops - on discussion topics. Things you got stuck on when you went home."
“Good Handout!! Web page class??"

"Great having a smaller class size."

"Need longer time."

"Please call if anything else is offered. Great class."

"Publicize (post) these courses. I learned a lot. Would like more"

"Appreciate the information about the databases available through the library website."

"It's worth paying for this workshop but it's FREE!"

A recurring theme in the evaluations were "I cant believe it is free" and "I paid much more for a similar course and could not learn". More amusing but certainly seriously were comments like "Do you do consulting? Can you help us out at home with our new computer? We are willing to pay!" We certainly fielded phone calls after the course and helped the patrons where possible.

\section{Conclusions}

One of the unexpected results from our experience with the workshops was that we had a non-homogenous audience taking our courses in several of the sessions. For example, we had some patrons with Internet browsing experience. Some had exposure to a word processor or even a spreadsheet. But a number of people did not even have the experience of using a GUI platform such as Windows and did not know how to use the mouse. It was evident therefore that in order to get a consistent set of audience we would have to enforce some prerequisites. With that in mind, for the totally inexperienced users, unique sets of courses were designed. For example we quickly designed a course dealing with Basic Skills for using the Keyboard and the mouse. This course was designed for patrons without any specific knowledge of a particular computer platform. We showed them how to activate the computer and run applications on the MS Windows PC platform. This course was called the Mousercizer. Such a course focused on eyehand co-ordination and provides practice on the basic use of a mouse for navigating

The Mousercizer course was very popular as well. We are now confident that that between the Mousercizer and the Basic Internet Skills course we have a set of two courses that serves our community very well.

In conclusion, the whole project was a success as evident from the satisfactory response from the participants. Also, the patrons were interested in other advanced courses and 
were inquiring when an advanced course would be offered. This was very satisfying and it motivated the instructor as well. The patrons appreciated the fact that the library offered such courses for free. From a research perspective we also realized that some our patrons are unfamiliar with even the basics of computing. While a lot of us take the "mouse" for granted, our initial experience and feedback resulted in our considering and offering a preliminary course such as "Mousercizer" for our seniors and absolute new uses.

With the success of Internet workshops and the positive feedback from the Westford community, we hope to offer more information literacy classes and are considering some traditional courses such as Word, PowerPoint, Excel, HTML, and Frontpage or Dreamweaver in addition to some non-traditional courses as Searching on the Internet for Information.

\section{References}

Lehnert, Wendy. (1998). Internet 101: A Beginner's Guide to the Internet and the World Wide Web, Reading: Massachusetts, Addison Wesley.
Bassi, Laurie J. (1999): Are Employer Recruitment Strategies changing: Competence Over Credentials. In "Competence Without Credentials", Nevzer G. Stacey, Project Manager. U.S. Department of Education Office of Educational Research and Improvement.

Microsoft (2000) Internet Explorer, Accessed November 1, 1999 at htp./Twww.microsolt.com/windows/ie/tour/basics/defauth.hmm

\section{Biographies}

Dina Kanabar is the Head of Systems and Automation at the JV Fletcher Library in Westford. She has her Masters in Library and Information Science from Simmons College in Boston and has 22 years of experience in the library systems of both USA and Canada.

Vijay Kanabar is a faculty member of Boston University, where he teaches Ecommerce, Web languages, Database Management and Project Management courses. Prof. Kanabar has authored more that 20 papers and 3 books in the areas of Information Systems and has 22 years of teaching experience in both USA and Canada. 